\title{
EVIDÊNCIAS E CIRCUNSTÂNCIAS - LUDWIG WITTGENSTEIN E A CERTEZA
}

\author{
Arturo Fatturi \\ Universidade Federal da Fronteira Sul
}

\begin{abstract}
RESUMO: Neste ensaio apresento algumas considerações quanto à determinada passagem da obra On Certainty de Ludwig Wittgenstein. Meu objetivo ao apresentar estas considerações é analisar o argumento de Wittgenstein quanto às diferenças entre evidências para a verdade de uma afirmação. Wittgenstein usa como exemplo para discutir a relação entre evidências e circunstâncias o caso de contradição entre George Moore e que ele denomina por "os católicos". O interessante nesta discussão é que Wittgenstein afirma que Moore seria contraditado pelos católicos e não "negado". A partir da contextualização desta discussão tento mostrar que existe uma ligação entre evidências para a verdade de uma afirmação e as circunstâncias particulares de onde retiramos estas evidências. Antes de incidir em relativismo quanto ao conhecimento, Wittgenstein nos mostra que as evidências são orientadas por nossa imagem de mundo. Para discutir este argumento apresento, primeiramente, uma contextualização da questão; num segundo passo discuto a contradição entre Moore e os Católicos. Minha intenção é mostrar que a contradição ocorre entre duas imagens de mundo. Por fim discuto e analiso a expressão "teria de me resignar" usada apor Wittgenstein no que diz respeito à diferentes imagens de mundo que podem entrar em conflito.
\end{abstract}

ABSTRACT: In this essay I discuss some considerations about a particular passage of Wittgenstein's On Certainty. My aim in presenting these considerations is to analyze Wittgenstein's argument about the differences between types of evidence for the "truth of a statement. Wittgenstein uses as an example to discuss the relationship between evidence and circumstances whem he focus on the contradiction between George Moore and who he calls Catholics. Interestingly in this discussion is that Wittgenstein says that Moore would be contradicted by Catholics and not "denied" for them. Considering the context of this discussion I will try to show that there is a link between evidence for the truth of a statement and the particular circumstances of where we took this evidence. We can consider that Wittgenstein is arguing for some kind of relactivism about knowledge but Wittgenstein shows that our evidences are guided by our image of the world. To discuss this argument I first present the background of the issue; a second step discuss what is the contradiction between Moore and Catholics. My intention is to show that the contradiction is between two world images. Finally I discuss and analyze the expression "I would have to resign myself" that Wittgenstein used with regard to the two different images (namely Moore and the Catholics) of the world that may be in conflict.

PALAVRAS CHAVE: Wittgenstein, certeza, evidências, conhecimento, linguagem. 
O livro composto pelos últimos escritos de Ludwig Wittgenstein denominado ${ }^{1}$ On Certainty, nos apresenta uma série de seções desenvolvidas em torno de questões suscitadas pelas leituras que Wittgenstein realizou com seu aluno e amigo Norman Malcolm ${ }^{2}$ a respeito de alguns ensaios de George Moore. Os ensaios de Moore motivaram a discussão em torno da compreensão filosófica da dúvida, das noções de certeza e justificação que temos quanto a verdade de certas afirmações. Alguns tópicos do texto foram, provavelmente, discutidos com o próprio Moore, uma vez que no prefácio os organizadores indicam que um dos textos de Moore, citado Wittgenstein, era considerado por este como um dos melhores artigos escritos por Moore e que o próprio concordava com tal ponto de vista. Ao mesmo tempo, considerando que o texto foi completado nos últimos dias de vida de Wittgenstein, ele não teve oportunidade de polir, acrescentar ou modificar seu escrito. Considerando o método de Wittgenstein para tratar das questões filosóficas, isto é, sua forma de escrever e corrigir os escritos e, novamente, reescrevê-los e coligir alguns destes escritos em diferentes conjuntos, os escritos que formam $O n$ Certainty constituem uma obra completa.

Podemos dizer que o texto é uma contínua tentativa de compreender o papel da certeza e da dúvida em nossas afirmações, do que estamos certos que são afirmações verdadeiras, das evidências que fornecemos para a verdade de nossas afirmações. Neste ensaio vou me dedicar, de maneira um tanto tópica, sobre uma passagem que me chamou atenção desde a primeira leitura de On Certainty. Acredito que esta passagem apresenta certas complicações para sua compreensão adequada ou, pelo menos, para uma tentativa de estabelecer com clareza as distinções que a mesma tenta elaborar. Minha tentativa aqui é de compreender a afirmação de Wittgenstein "teria de me resignar"

\footnotetext{
${ }^{1}$ Editado por G E M Anscombe e G H von Wright, interessante notar que o material se constitui do tratamento de um único tópico e, portanto, não é uma seleção de seções escolhidas pelos editores. O próprio Wittgenstein havia marcado estas seções em seus notebooks. Considerando o processo de escrita e preparação de Wittgenstein para seus escritos, On Certainty é uma obra quase no mesmo estado de publicação que o Tractatus Logico Philosohicus.

${ }^{2}$ Conforme relatado por Ray Monk em Wittgenstein: The Duty of Genius, Penguin Books, $1991 \mathrm{e}$ Oets Kolk Bouwsma em Wittgenstein's Conversations 1949-1951, Hackett, Indianapolis, 1986. As seções iniciais de On Certainty apresentam argumentos discutidos por Moore em Proof of an External World de 1939 e A Defense of Common Sense de 1925.
} 
quando nos vemos diante de alguém que possui convicções que estão em desacordo com as nossas. A expressão "teria de me resignar" aparece $^{3}$ no contexto da discussão de On Certainty no momento em que Wittgenstein argumenta que uma controvérsia em que ideias fundamentais estão em conflito devido a uma afirmação paradoxal como "a terra não existia antes de meu nascimento". Neste caso quais as convicções estariam em descordo se contradissemos esta pessoa? Se as convicções fundamentais estão em desacordo, restaria a resignação para quem nega o que aquela pessoa afirma.

Primeiramente, vou fornecer alguns esclarecimentos que contribuirão para a compreensão do problema que pretendo tratar. A certa altura do texto de On Certainty, Wittgenstein analisa a possibilidade de duvidar de certas proposições as quais reputamos como indubitáveis. Esta indubitabilidade seria fornecida a estas proposições devido ao seu papel de fundamento de nossos raciocínios. Junto a tal característica, Wittgenstein considera nossa possibilidade de elaborar certas afirmações que não saberíamos como compreender completamente 4 por exemplo, "a uma hora atrás esta mesa não existia”, "seres humanos possuem pais humanos", etc. Quanto à proposição que afirma que os seres humanos possuem pais humanos, por tudo que sabemos, possuem pai e mãe (OC, \#239), ainda que exista o caso,pondera Wittgenstein, de pessoas que acreditem que existam seres humanos sem pais e não dão crédito para as evidências contrárias. Neste ponto ele cita o caso dos Católicos que acreditam que Jesus Cristo possuía apenas mãe humana e que também acreditam que, em certas circunstâncias, o pão e o vinho na Missa mudam completamente de natureza, mesmo que toda evidência prove o contrário. Conforme argumenta Wittgenstein se Moore afirmasse para eles (os Católicos) quanto às duas espécies: "Eu sei que isto é vinho e não sangue", os Católicos o contraditariam ${ }^{5}$.

$\mathrm{O}$ que considero intrigante nesta passagem é o fato de que Moore, conforme exemplifica Wittgenstein, ao dizer que sabia que era

\footnotetext{
${ }^{3} \mathrm{OC} \S 238$

${ }^{4}$ Por exemplo, a afirmações como "a uma hora atrás esta mesa não existia", "esta montanha não existi a meia hora atrás", etc.

${ }^{5} \mathrm{O}$ termo usado por Wittgenstein é widersprechen, que pode ser traduzido como contradizer, contraditar, opor-se, contestar, protestar.
} 
vinho e não sangue estaria afirmando algo que não era uma falsidade. Isto é, que quando observamos o vinho que é servido na Missa Católica o que vemos e sabemos que está a nossa frente é um líquido que reputamos, acreditamos - por tudo que sabemos - ser vinho. Portanto, Moore, tanto quanto nós (se fosse o caso) estaria garantido, por certas evidências comuns, ao afirmar que sabia ser aquele líquido vinho e não sangue. Ao mesmo tempo, chama atenção o tipo de situação escolhida por Wittgenstein a qual implica que os Católicos diriam algo contrário ao que Moore - e talvez nós na mesma situação - diz que sabe. Quando Moore afirmasse "Eu sei que isto é vinho", receberia como resposta uma afirmação que contraditaria o que diz, isto é, "não, isto é sangue". Chamo atenção para o fato de que Wittgenstein usa a palavra "contraditar" e não "negar" e isto, por sua vez, pode ser considerado como implicando que numa mesma situação ou para compreender a verdade de uma afirmação, são possíveis dois tipos de evidências as quais seriam incompatíveis entre si.

Este tipo de situação que serve de pano de fundo para a discussão de afirmações como "Eu sei que..." e o que as contraditaria, o fato de que Wittgenstein usa como exemplo o caso de um dos ensinos do Catolicismo que tem como fundamento os escritos do Novo Testamento. Ao mesmo tempo, este ensino difere de outras denominações Cristãs que consideram as mesmas passagens do texto do Novo Testamento de outra forma. Por exemplo, Luteranos e Calvinistas não diriam que eles sabem que não é vinho, uma vez que está envolvida a discussão da presença real de Jesus Cristo como sangue e vinho na Missa.

Ao que tudo indica, Wittgenstein usa propositadamente o caso da doutrina Católica ${ }^{6}$ para exemplificar os problemas filosóficos que cercam a expressão "Eu sei que..." quando visa ser uma afirmação de conhecimento. Ao mesmo tempo, o que pode ser tema de consideração são as evidências que uns e outros apresentam para a verdade de suas

\footnotetext{
${ }^{6}$ Sabemos através dos textos publicados e preparados por alunos e amigos pessoais de Wittgenstein que ele possuía profundo respeito pelos ensinamentos do Catolicismo e se considerava uma pessoa religiosa, ainda que não praticante. Ver por exemplo o texto de Norman Malcolm Wittgenstein: A Religious Point of View, Cornell Unversity Press, 1994, editado por Peter Winch e as Vermische Bemerkungenm, edidato por G. H. von Wright, que estão repletas de passagens sobre a fé Cristâ.
} 
afirmações. No caso em discussão, quais as evidências que Moore poderia fornecer para sua afirmação de que o que ele observa, nas duas espécies, é algo que ele pode dizer que sabe ser pão e vinho?

Por outro lado, se os Católicos, tal como afirma Wittgenstein, contraditariam Moore, então eles devem possuir evidências diferentes das de Moore para a verdade do que dizem. Mas o que seria uma "evidência" para que durante a Missa Católica, as duas espécies são "carne" e "sangue" e não "pão" e "vinho"? Qual a relevância fornecida à esta situação pela expressão "contraditar”? Além disto, somos treinados ou educados para considerar que as crenças religiosas não possuem provas além das que são baseadas na fé e esta, por sua vez, não presta contas à realidade que se pode observar.

Ou seja, tratando-se de crenças religiosas em comparação com as crenças que visam ser verdadeiras e justificadas através de evidências epistêmicas, é plausível que consideremos a maioria das crenças do Catolicismo como "contrárias às evidências", isto é, por tudo que sabemos seres humanos possuem pais humanos e o pão e o vinho sempre são a mesma substância quando guardados por certo tempo e conforme condições normais ou adequadas. Segundo nossa experiência, temos evidências quanto a isto que sabemos. Contudo, no caso dos católicos (e da maioria dos Cristãos) eles diriam algo contrário às evidências e que, em certas circunstâncias, o vinho não é vinho e que o pão não é pão (ainda que em momento algum os católicos afirmem que o pão, tal como o conhecemos ordinariamente, não é pão). Creio que o que até aqui mostrei serve como contexto para compreender a disputa que Wittgenstein apresenta entre dois tipos de evidências que permitiriam contraditar afirmações.

\section{1.}

O que torna interessante o exemplo usado por Wittgenstein é que reputamos ou consideramos as afirmações que se sustentam na fé como impossíveis de serem provadas e, com isto, inadequadas para fornecer fundamentos para a verdade das afirmações ${ }^{7}$ que nelas se

\footnotetext{
${ }^{7}$ Ainda que nas suas conversas sobre crença religiosa transcritas por Cyril Barret, Wittgenstein
} 
fundamentam. Assim, por exemplo, justificar a crença de que Jesus teve apenas mãe humana, implica fornecer justificativa e evidências que são oriundas da fé ou da própria crença religiosa. Ainda, quando se trata de considerar uma afirmação como "contraditória" a outra, estamos lidando com uma circunstância restrita, a saber, as circunstâncias que dizem respeito ao que é afirmado pelas duas proposições. Ou seja, as duas proposições que se contraditam devem possuir um mesmo contexto e conteúdo informacional. Para tornar mais claro o que estou pretendendo contrastar consideremos o seguinte exemplo: se uma afirmação diz "o fundador da Universidade federal de Santa Maria é José Mariano da Rocha Filho”, pensemos no que sustentaria a verdade de tal afirmação. $O$ que sustentaria uma afirmação que contraditasse a mesma?

Obviamente que poderíamos recorrer, para dirimir dúvidas e apresentar justificações, à documentação disponível e a história da fundação da Universidade em questão, a biografia de José Mariano da Rocha Filho. Ou seja, buscaríamos um tipo de prova que se situaria nas mesmas circunstâncias, isto é: documentos, testemunhas e a história. $\mathrm{O}$ mesmo se daria com uma afirmação como, por exemplo, de que determinado corpo possui 50 quilogramas, isto é, contraditá-la implica em encontrar sustentação em evidências que se opunham a ela. Para tanto, teríamos de recorrer a alguns expedientes que se situariam nas mesmas circunstancias das duas afirmações contraditórias entre si. Mas não aprece ser este o caso com a contradição que os Católicos apontariam a Moore.

O que Moore diz que sabe, possui evidências específicas que todos nós reconhecemos, quais sejam: que sabemos as diferenças entre sangue e vinho por nos terem ensinado, que aprendemos a lidar com vinho e não é a mesma forma como lidamos com sangue, que é possível doar sangue e tal doação é completamente diferente da doação

argumente favoravelmente à compreensão da crença religiosa. Segundo ele, quem crê no julgamento final ou no renascimento da alma para um julgamento final, tal como ensinado no Cristianismo, faz isto com base numa crença inabalável. Tal crença se mostra não por apelo a fundamentos ordinários. Antes, tal crença regula toda a vida da pessoa. Lectures and Conversations, pg. 53 - 54. Portanto, para Wittgenstein a crença religiosa enquanto ligada à regulação da vida produz crenças que são firmemente fixadas. Este fundamento não seria uma doutrina teológica e sim a própria vida do "crente". 
de vinho, que a composição química do vinho é diferente da composição química do sangue, e assim por diante. Mas o que os Católicos usam como fundamento para contraditar Moore não está no mesmo espaço de evidências ${ }^{8}$ que a afirmação de Moore daquilo que sabe (isto é, que ele sabe que é vinho). Ou seja, se fosse perguntado aos Católicos como sabem que é sangue, eles alegariam evidências oriundas de convicções completamente diferentes das convicções de Moore para garantir suas evidências de que o que vê é vinho, de que sabe que é vinho.

A expressão que estou usando aqui como "mesmo espaço de evidência" é a tentativa de dar sentido à contradições para determinadas proposições. Por exemplo, proposições empíricas possuem certas justificativas e evidências, contraditá-las exige que forneçamos razões que se situem no mesmo "espaço" de justificativas e evidências". Tomemos como exemplo de "espaços diferentes de evidência" o seguinte: alguém afirma que é verdade a seguinte proposição "Santa Maria está a 395 quilômetros de distância de Chapecó”, tal afirmação pode ser contraditada a partir de um conjunto de evidências aceitáveis para a mesma, por exemplo: medições feitas por alguém, dados de satélites, dados de empresas de transporte, testemunhos de motoristas, entre outras. Contudo, não aprece ser aceitável contraditar tal afirmação com base em evidências oriundas de leituras de cartas, aparições místicas e comunicação com espíritos. Tais evidências ocupam outro espaço em nossas convicções. Ou seja, contraditar a a firmação de que Santa Maria dista de Chapecó 395 quilômetros a partir de evidências se assim se pode chamar - oriundas de leituras de cartas é fundamentar alegações baseadas numa série de convicções que não permitem evidências válidas para afirmações sobre distâncias entre cidades. Como convencer alguém que recorre à leitura de cartas para determinar

\footnotetext{
${ }^{8}$ Ou convicções (Überzeugungen) tal como Wittgenstein usa esta expressão na seção 238 de $O n$ Certainty.

${ }^{9}$ Tentando ser mais direto quanto a esta questão, seria o mesmo que dizer que proposições empíricas apenas podem ser contraditadas por outras proposições empíricas. O que chama atenção no caso que estou apresentando é que a afirmação de Moore é empírica, enquanto que a afirmação que a contradita - pronunciada pelos Católicos - não parece ser empírica e sim pertencer a um outro espaço, por assim dizer.
} 
distâncias entre cidades e que está convencida de que este é o método ${ }^{10}$ correto? O que teríamos de lhe fornecer como evidência de que ela não está correta, iria contra não apenas de suas afirmações, mas de suas convicções.

\section{2.}

A passagem em que Wittgenstein afirma que Moore seria contraditado pelos Católicos parece ter algo em comum com esta possibilidade, qual seja a possibilidade de que contraditar uma afirmação que alguém faz, não seria simplesmente mostrar que as provas que tem não são válidas enquanto tais, mas que as evidências que esta pessoa possui para garantir a verdade do que afirma, não são adequadas. Retomando o caso questão, se Moore pedisse provas aos Católicos, estes lhe forneceriam explicações e evidências de um âmbito diferente daquele que Moore esperaria. Ou seja, alegariam evidências válidas em determinadas circunstâncias mas, tais evidências não seriam aceitas por Moore, uma vez que ele consideraria aptas somente evidências baseadas no que a observação de objetos pode fornecer. Ao mesmo tempo, parece que uma afirmação como a de Moore ("eu sei que isto é vinho", "eu sei que isto é pão”), para ser contraditada necessita de evidências dos sentidos ou da percepção. Estas evidências, provavelmente, seriam as que Moore aceitaria para provar que sua observação não estava correta.

Gostaria de ressaltar, que não é minha intenção afirmar (ou fazer algum tipo de comparação) que a doutrina Católica se parece com a leitura de cartas ou comunicação com espíritos, mas sim que ela não pertence ao mesmo espaço de evidências (ou circunstâncias de evidências) que a afirmação de Moore exige para ser contraditada, se é

\footnotetext{
${ }^{10}$ Usei este exemplo a fim de ilustrar o uso da expressão "diferentes espaços de evidências". Não é minha intenção afirmar que a crença ou os ensinamentos Católicos são idênticos ou equivalentes à "leitura de cartas", "aparições místicas" ou "comunicação com espíritos". O ensinamento católico é diferente deste tipo de manifestação de credulidade e animismo quanto à fenômenos paranormais. Isto devido ao fato de que estas manifestações são vivências de fenômenos naturais, isto é, algo bem diferente do que subjaz como fundamento do ensino católico.
} 
que estou correto em tomá-la como circunstância de evidências que contraditaria o que diz Moore no exemplo oferecido por Wittgenstein. O que estou buscando compreender é como a a firmação "eu sei que isto é vinho" pode ser contraditada, nas circunstâncias oferecidas naquela seção de On Certainty. Meu objetivo com os exemplos paralelos que forneci, foi o de mostrar que, tal como fomos treinados ou ensinados as afirmações provenientes da crença religiosa não possuem as mesmas evidências que as afirmações provenientes de nossa observação de objetos ou fatos. Mesmo que alguém alegue saber a distância entre duas cidades através da leitura de cartas e que, no seu caso, as cartas são seu objeto de observação, ela estaria usando a expressão "observação" de forma diferente do uso normal.

Consideremos que ocorresse uma discussão quanto à certeza da distância entre duas cidades e que, ao mesmo tempo, uma afirmação fosse proveniente de leituras de instrumentos de medição e outra fosse fruto da leitura de cartas (por exemplo), neste caso não estaria em questão o que ambas as pessoas observam, pois ambas observariam determinados objetos, saber, uma pessoa observaria certos instrumentos de medição, enquanto que outra observaria certas figuras (ou números) escritas num conjunto de cartas. A questão seria considerar como compreender as evidências quanto às afirmações sobre as distâncias que são fornecidas pela leitura de instrumentos de medição e as evidências para o mesmo resultado quando este é obtido através da leitura de cartas.

\section{3.}

Talvez a questão das diferenças entre Moore e os Católicos possa ser encarada por outro ponto de vista. Por exemplo, tanto Moore quanto os Católicos sabem aquilo que afirmam, tanto que se contraditam. Mas, o que seria saber nestas circunstâncias? Tudo se passa como se a afirmação de saber tivesse como fundamento um conjunto de evidências que se justapõe ou que se apoiam e, mais ainda, que este conjunto de proposições nos fornece a certeza. Mas, contudo, não seriam estas evidências fruto de convicções? Por exemplo, usando as palavras de Wittgenstein, se alguém me diz que a Terra não existia antes 
de seu nascimento, teria de perguntar a esta pessoa em que ela se fundamenta para ter tal crença ou elaborar tal afirmação. Com isto poderia avaliar com quais das minhas convicções esta pessoa estava em desacordo. Se tal pessoa, diz Wittgenstein ${ }^{11}$, estivesse em desacordo com minhas convicções fundamentais, eu teria de me resignar ${ }^{12}$. Mas com que estaria me resignando? Com o fato de que estaríamos sempre em contradição entre nós? Mas isto deve ser assim?

Claro que eu poderia alegar que minhas crenças de que a terra não pode ter existido apenas a partir do nascimento desta pessoa, são baseadas na experiência, uma vez que a experiência mostra que isto não é assim. O mesmo poderia Moore alegar aos Católicos que creem que existiu um ser humano que tinha apenas mãe humana, isto é, a experiência mostra que todos os seres humanos têm pais humanos. Entretanto, pergunta Wittgenstein, seria isto uma prova? Seria a experiência a base segura para minha convicção ${ }^{13}$ ? Talvez o saber pela experiência seja apenas a confirmação de uma hipótese na qual eu acredito e, desta forma, sempre a vejo confirmada pela experiência cada vez que verifico que esta é minha crença eu posso afirmar ${ }^{14}$ "creio nisto com certeza”. E se as questões continuassem sobre como sei que tal crença será verificada na experiência não teria como justificar a não ser alegando, novamente, que sempre foi verificada. Isto é, estou convencido de que a experiência sempre mostrará isto.

Assim, uma forma de compreender como os Católicos contraditam Moore é pensar que as circunstâncias nas quais sabem que sua crença é verificada são plenamente ligadas às suas convicções e que para além destas não há recuo. As convicções seriam a base de suas certezas e não um conjunto de afirmações cujas justificativas pudessem ser estabelecidas através da prova ou demonstração de suas verdades. Neste caso, bem como em muitos outros, a convicção é um agir convencido da verdade daquilo ou naquilo que se crê. Os Católicos estão convictos do que sabem e por tal motivo podem contradizer Moore. Entretanto, esta contradição não se dá no nível da verdade das

\footnotetext{
${ }^{11} \mathrm{OC}, \S 238$.

${ }^{12} \mathrm{OC}, \$ 238$

${ }^{13} \mathrm{OC}, \$ 240$

${ }^{14} \mathrm{OC}, \$ 242$
} 
afirmações em disputa e sim no nível das convicções que ambos possuem.

É possível dizer isto de outra maneira: minhas convicções me levam a estar certo disto, uma vez que minha certeza se funda em evidências. Neste caso o que se está alegando, seguindo tal raciocínio, é que as convicções são anteriores às evidências. Tudo se passaria como se as evidências tivessem como fundamento convicções que temos e estas convicções, por sua vez, não teriam fundamento. Segundo tal ponto de vista, se pretendêssemos duvidar da existência da terra antes de nosso nascimento, teríamos de duvidar de todas as outras coisas que são pontos assentados para nós ${ }^{15}$ (ou pontos assentes). Ou seja, coisas que consideramos que sabemos com certeza. A afirmação de que a Terra existe a muito mais tempo do que nós, não é apenas uma proposição a que nos agarramos, como diz Wittgenstein, ela implica em um conjunto de proposições (OC, §225). Ela é a proposição da qual temos certeza, pois desempenha um papel importante no que fazemos.

Alguém poderia argumentar que os pontos assentes para nós ou aquilo que temos como evidente são assim considerados por temos uma forma de justificar os mesmos. Consequentemente, o caminho para que possamos afirmar que sabemos que algo é o caso, seria o de mostrar que temos certeza do que sabemos e que esta certeza está fundada em nossas evidências seguras, este seria o caminho para a justificação. Contudo, Wittgenstein inicia a segunda parte do texto de On Certainty afirmando 16. "Evidência segura é a que aceitamos como segura, é a que nos orienta quando agimos com segurança, quando procedemos sem qualquer dúvida”. Ou seja, nossa certeza se baseia não em proposições comprovadamente verdadeiras e que podemos provar que são desta forma, mas em certezas que são a base de nosso procedimento. $\mathrm{Ou}$ melhor, o nosso procedimento exige que algumas proposições não sejam questionadas e sim, consideradas como

\footnotetext{
${ }^{15} \mathrm{OC}, \S 234$. Nesta seção Wittgenstein usa a expressão "was mir festeht”. Na tradução inglêsa foi usada "stands fast for me". Conforme comenta Myoal-Sharrock em Understanding Wittgenstein (pg. 13), Wittgenstein usa esta expressão como equivalente à certeza. No original em Alemão "gewissheit".

${ }^{16} \mathrm{OC}, \$ 193$ a. Cabe notar que nesta passagem a tradução para o português não apresenta o itálico do original Alemão nem da tradução para o Inglês. Wittgenstein grafou a expressão "handeln" que pode ser traduzida também por "proceder", "agir", "tratar". Optei pela expressão "proceder".
} 
assentadas.

Por certo que existe justificação, mas como afirma Wittgenstein, a justificação tem um fim e este fim se encontra em nossas convicções. Segundo meu ponto de vista é a devido a isto que os Católicos podem contraditar Moore, isto é, eles não aceitariam as evidências que Moore crê que forneceriam a ele a certeza para afirmar "eu sei que é vinho e não sangue". Uma vez que eles teriam evidências de que a afirmação "é sangue e não vinho" possui evidências, as quais estão ligadas às convicções que partilham. Moore teria de resignar-se, como afirma Wittgenstein no caso das contradições entre convicções fundamentais (OC, §238). As convicções dos católicos são de que naquelas circunstâncias o que se vê não é vinho e sim sangue e eles poderiam alegar que tem evidências para tanto. Moore, contudo, não compreenderia estas evidências como válidas, uma vez que suas convicções lhe indicam evidências diferentes.

Entretanto, este resultado não parece de todo esclarecedor ou satisfatório e, plausivelmente, se poderia argumentar que considerando que a afirmação de Moore seria contraditada devido à diferença entre convicções, que as evidências de Moore não seriam consideradas como tais pelos Católicos, parece que tudo isto já estava contido na própria possibilidade de afirmar que aquilo que para os Católicos é sangue, Moore sabia que era vinho. Isto é, Moore não era Católico e sendo assim a diferença entre ele e os Católicos se dá na crença de um e outros. Moore não crê no que os Católicos creem e, para estes, naquelas circunstâncias seria evidente que era sangue e não vinho. Entretanto, se dizemos que as evidências que Moore e os católicos podem apresentar para suas afirmações são provenientes de convicções diferentes, não seria o caso de deslizarmos para uma espécie de Relativismo? Ao fim e ao cabo, se todos possuem evidências diferentes para casos iguais e se estas evidências validam as diferentes afirmações, então por qual razão poderíamos dizer que Moore estava errado? Ou, por outras palavras, se a verdade das afirmações depende das evidências que se pode fornecer e em se tratando de um mesmo caso (vinho/pão, corpo/sangue), então não poderíamos dizer que Moore ou os Católicos estavam errados, pois ambos possuem evidências diferentes. Mas, a insatisfação que sentimos ao analisar estas diferenças sob tal ponto de vista é proveniente da afirmação de Wittgenstein de que os Católicos contraditariam Moore. 
Bem, uma das alegações que Moore poderia fazer seria a seguinte: ora, sei que a a firmação "isto é vinho", é verdadeira por ser verdadeira em todos os casos como este, isto é, quando estou diante deste tipo de substância, com estas e estas características. Ou seja, a afirmação concorda com os fatos. Contudo, se poderia dizer quanto a isto que isto, quero dizer, que a proposição concorda com os fatos, pode nos esclarecer o que significa "concorda com os fatos", mas que mesmo assim, não se sabe o que fazer com isto ${ }^{17}$. Ou seja, que a afirmação "isto é vinho" é verdadeira por concordar com os fatos, pode ser considerado como mostrando que temos um critério de verdade para proposições ${ }^{18}$, qual seja: de que proposições, para serem verdadeiras (e no caso contrário, para serem falsas) devem estar de acordo (se falsas, em desacordo) com os fatos.

Entretanto, deixou-se de lado o que significa "acordo" (isto é, seria necessário definir em que consiste "acordo com os fatos”). Não devemos esquecer que, certamente, os Católicos concordariam que a afirmação "isto é vinho" em determinadas circunstâncias concorda com os fatos. Mas em circunstâncias específicas esta mesma afirmação pode ser contraditada. Continuando ainda com a argumentação de Wittgenstein, poderíamos dizer que a verdade ou não da proposição significa que tomaremos uma atitude (decisão=Entscheidung) quanto à mesma, a partir disto ${ }^{19}$. Contudo, qual seria o fundamento para nossa ação (decisão=Entsheidung)? Não é suficiente que estabeleçamos um critério para o que consideramos como proposição verdadeira ou falsa, este critério deve ter algum papel ou função no que faremos com as proposições que assim pudermos classificar. Tal como afirma Wittgenstein em OC §204, a justificação da evidência tem fim, mas este fim não consiste na apresentação de proposições que reputamos como verdadeiras (ou daquelas últimas proposições conforme a ou uma ordem de fundamentação), antes, é a forma como atuamos que garante o jogo de linguagem da justificação. Se alguém pergunta se cremos que é de fato verdadeiro que a terra existia muito antes de nosso

\footnotetext{
${ }^{17} \mathrm{OC}, \S 03 \mathrm{a}$.

${ }^{18} \mathrm{OC}, \S 199$. A razão por que o uso da expressão "verdadeiro ou falso" é um tanto enganadora é que equivale a dizer "ajusta-se aos fatos ou não" e o que verdadeiramente está em questão é o que significa aqui "ajustar-se".

${ }^{19} \mathrm{OC}, \S 200$
} 
nascimento, diríamos que sim e se continuasse a exigir razões fundamentais, lhe diríamos "não posso lhe apresentar razões fundamentadas, mas se você aprender mais, também pensará o mesmo" (OC, §206). E mais adiante acrescenta: a existência da terra é parte da imagem total que forma o ponto de partida de todas as minhas convicções (OC, §209).

Aqui surge um ponto interessante no que diz respeito a toda a argumentação de Wittgenstein em On Certainty, a saber: que a justificação do que sabemos ser verdadeiro se apoia não em outras proposições que consideramos verdadeiras ou falsas. $\mathrm{Na}$ forma (maneira, papel) com que estas proposições se encaixam em toda uma imagem de mundo, subjaz às nossas evidências (OC, §251). Assim, por exemplo, se alguém duvidasse da idade da Terra e afirmasse que esta tem apenas 20 anos de idade, não saberíamos corretamente como convencer tal pessoa, não saberia claramente em que conjunto de convicções apoia suas evidências para tentar compreender o que ela afirma.

Podemos imaginar uma pessoa que tenha sido educada de tal forma que acredita, através deste ensino, que a Terra tem apenas poucos anos, seria possível ensinar-lhe que a Terra tem muito mais tempo. Para isto lhe forneceríamos algumas evidências e tentar ensiná-lo que a terra existe a tantos e tantos anos e, com isto, afirma Wittgenstein, estaríamos a dar-lhe nossa imagem de mundo (OC, §262). Mas, para que isto fosse levado a cabo, estaríamos persuadindo (Überredung) a pessoa a aceitar nossa imagem de mundo e não apenas lhe fornecendo proposições que acreditamos serem verdadeiras segundo uma ordem de demonstração. Nosso ensino poderia chegar ao fim e a pessoa não aceitar o que lhe ensinamos.

Neste caso, não a persuadimos e teríamos de nos resignar com o fato de que esta pessoa não consegue ver como evidências o mesmo que nós vemos. Esta pessoa tem uma imagem de mundo da qual não pretende abrir mão. Sua imagem de mundo, tanto quanto a nossa, é a base de suas convicções, sua forma de agir para com o mundo. 


\section{Conclusão}

Bem, o que tentei aqui foi traçar um caminho para compreender uma determinada passagem de On Certainty, talvez o que eu tenha fornecido nada mais seja que um esboço de um possível caminho. Um outro caminho seria analisar a afirmação que, segundo Wittgenstein, Moore poderia usar a saber, "Eu sei que isto é vinho" a partir do ponto de vista da análise de Wittgenstein da expressão "Eu sei que...". Contudo, isto é um motivo a ser tratado em outro momento. Outro ponto que se pode derivar do que apresentei aqui é perguntar se se pode inferir dos argumentos de Wittgenstein que imagens de mundo apenas podem ser "mudadas" através da persuasão (Überredung), isto é, as certezas e os "bons fundamentos" pertencem a imagem de mundo.

Na seção 611 de On Certainty, Wittgenstein fornece um exemplo do que entende por persuasão: "Pensem no que acontece quando os missionários convertem os nativos". Consideremos este exemplo fornecido por Wittgenstein: quando os missionários convertem povos nativos ao Cristianismo eles fazem com que certas convicções sejam modificadas, ainda que o estado do mundo continue o mesmo. Ou seja, se os Missionários convertem o povo nativo $\mathrm{X}$ a não mais celebrar rituais com sacrifícios de animais, nem por isto eles mudaram a forma como o povo nativo considera os animais. O que foi mudado, através da conversão, foram as convicções quanto à prática sacrificial de animais.

Ao mesmo tempo, ao introduzirem as práticas Cristãs os Missionários ensinam ao povo nativo uma nova situação que lhes fornece outras evidências para o que lhes foi ensinado acreditar. Por exemplo, antes dos Missionários realizarem a cristianização do povo nativo $\mathrm{X}$, um animal ou determinado tipo de animal era visto como sendo uma possível vítima sacrificial. Mas, após a cristianização, as convicções do povo nativo, quanto aquele tipo de animal, foram "convertidas" e lhes fornece outras evidências para tratar com o mesmo tipo de animal. Contudo, não se pode afirmar que os Missionários "ensinaram convicções" através da verdade de determinadas afirmações ${ }^{20}$.

\footnotetext{
${ }^{20}$ Por exemplo, que a afirmação que diz que os animais não merecem ser sacrificados é
} 
Os Missionários ao converterem o povo nativo em questão realizaram mudanças nas convicções deste povo. Estas convicções os conduzem agora, a elaborar afirmações diferentes sobre os sacrifícios cerimoniais com animais. Outros povos que não sofreram mudanças em suas convicções, que $\mathrm{n}$ possuirão outras formas cerimoniais. A situação das convicções de ambos os povos nativos é diferente e, portanto, suas evidências também serão diferentes. $O$ que se deve ressaltar é que estas diferenças não se devem à posse da verdade por parte de um povo em comparação ao outro, uma vez que os Missionários mudaram as convicções de um povo através do convencimento e não através do método de prova da verdade das afirmações que usavam para efetivar a conversão.

Mesmo que se considerem as mudanças de comportamento cerimonial devido à força, com no caso de vários povos colonizados que foram proibidos de realizar certos cultos cerimoniais, a imagem de mundo não é mudada e sim se proíbe agir conforme esta imagem. Mas isto, contudo, é outra questão. A proibição do cerimonial não é uma mudança na imagem de mundo, talvez a proibição seja uma expressão da impossibilidade de resignar-se diante de uma impossibilidade de "conversão".

Bem mais adiante no texto de On Certainty, encontramos a seguinte passagem que faz parte da tentativa de responder a uma pergunta lançada pelo próprio Wittgenstein, a pergunta era "Será errado que me guie nas minhas ações pelas proposições da Física?” Imediatamente Wittgenstein faz a seguinte consideração que servirá de resposta a esta pergunta: "suponha que encontremos pessoas que não considerem [estas proposições] como razões reveladoras (telling reasons). Então, como podemos imaginar isto? Em vez de consultar um Físico eles consultam um oráculo. (E por isto os consideramos primitivos) É errado para eles consultar um oráculo e ser guiado pelo mesmo? Se chamamos a isto por "errado" não estaremos nós usando nosso jogo de linguagem como base para combater o deles?” (OC, $\S 609$ ). Estamos certos ou errados em combater o mesmo? (OC, §610)

verdadeira; que é verdadeira a afirmação que diz que deuses que exigem sacrifícios não são bons para a humanidade, etc. 


\section{Bibliografia.}

BOUWSMA, Oets. K. Wittgenstein Conversations, 1949 - 1951, Indianapolis, Hackett, 1986. Edited by J.L. Craft e Ronald E. Hustwit. MONK, Ray. Wittgenstein: The Duty of Genius, Penguin Books, London, 1991.

WITTGENSTEIN, Ludwig. On Certainty, New York, Harper Torchbooks, 1972

WITTGENSTEIN, Ludwig. Philosophical Investigations, Oxford, Blackwell, 3rd Ed., 2001. 